\title{
The Mediating Effect of Creative Thinking on Multiple- Intelligence and Thinking Patterns Among 10th-Grade Students in Abu Dhabi Private Schools
}

\author{
Ali Mohammed Ahmed Dawahdeh \\ Ph.D. Ed., Faculty of Education and Human Development, \\ Sultan Idris Education University, Perak, Malaysia \\ Mohammed Yousef Mai \\ Lecturer, Faculty of Education and Human Development, \\ Sultan Idris Education University, Perak, Malaysia
}

\section{Abstract}

This study aimed at investigating the mediating effect of creative thinking on multiple-intelligence and thinking patterns among 10th-grade students in Abu Dhabi private schools. This study used descriptive approach and SEM. Also, the study sample consisted of 350 students from five private schools in Abu Dhabi. The instruments used were Gardner's multiple-intelligence scale and thinking patterns scale. Data was analysed using descriptive statistics, correlation coefficient and Amos. The results showed significant positive relationship between multiple intelligences (IV) and thinking patterns (DV) through creative thinking (MV). Direct significant positive relationships were found between interpersonal intelligence (IV) and thinking patterns (DV) $(\mathrm{r}=.241)$; natural intelligence (IV) and thinking patterns (DV) $(\mathrm{r}=.113)$; musical intelligence (IV) and thinking patterns (DV) ( $\mathrm{r}=.000)$; bodilykinaesthetic intelligence (IV) and thinking patterns (DV) $(r=.000)$. In conclusion, the findings revealed the influence of creative thinking on the relationship between multiple-intelligence and thinking patterns.

Keywords: multiple intelligences, thinking skills, tenth-grade, thinking patterns, creative thinking 


\section{Introduction}

Teaching thinking skills is very important for school students because they are the new generations. Schools should do everything they can to provide thinking opportunities to their students. Moreover, many teachers consider the task of developing the student's ability to think as an educational goal that they place at the top of their priorities (Jarwan, 2007). Developing thinking would develop the learning (educational) process, as it makes students more aware of their mental processes.

Thinking skills must be learned through human sciences in order not to be misused. The instrumental enrichment program is one of the worldwide programs applied to develop thinking skills, it relies on independent subjects that are not based on a specific context, and its results showed a great ability to the non-verbal deduction and this proved that thinking can be taught (Al-Otaibi, 2007). On the other hand, thinking is a goal of education, and thus, the development of thinking is an important educational function for all institutions to help the learner in dealing with this era of information, which requires individuals with mature mentality, objective outlook of ideas and attitudes, and search for reasons and evidences. Thinking is a necessary process to establish a democratic life and achieve scientific and social progress. (Ruzzuqi \& Abdul-Karim, 2015).

The importance of thinking is vital to discover the universe and has a great role in life and learning success. It also improves the student's achievement level and gives him/her a sense of control over his/her thinking stemming from the achievement level which makes him/her feel confident. The elements of thinking include visualization, imagination, symbolizing, muscle activities and brain functions (Jarwan, 2014). However, educators see that the elements and tools of thinking are to expand the student's horizons by looking at ideas including the pros and cons, organizing the ideas of the learner through analyzing the problem to primary and secondary procedures, identify the similarities and differences between the phenomena as well as the interaction between ideas, and provide the environment that helps to stimulate thinking. Educators agreed upon the following thinking patterns: scientific, empirical, logical, high-level, creative, critical, analytical, deductive and reflective thinking.

The interest in the development of creative thinking is one of the priorities of educational issues in the Arab world. Many studies and researches emphasized the role of the teacher in developing creative thinking among students, including the International Conference on Thinking (1997) and Education Curriculum and Development of Thinking Conference (2000). The Development of Arab Creativity Community made a training workshop that included the development of creative 
thinking skills and the importance of developing the human mind. The theories of mental formation, which tried to interpret intelligence, differed, reflecting the believers' visions of these theories of mental formation on one hand as well as reflecting the developments of methods of measurement and evaluation, and the statistical methods used on the other hand, where psychologists took a variety of ways to understand intelligence and its nature (Abu-Hashim, 2007). Multiple intelligences are not limited to one or two types of intelligences, but rather to several types of intelligences that include many aspects of students' lives in school and in real life.

Also, intelligence does not have one fixed ability measured by single measure to be determined. However, multiple intelligences are not just preparations, abilities or talents. To illustrate, Gardner suggested at the evolution of multiple intelligences that each individual possesses these intelligences in varying degrees and has a unique combination of these intelligences that can be improved to varying degrees. Moreover, Gardner showed in his book "Frames of Mind" a new concept of intelligence as an ability of solving the problems faced by the individual with unique and creative abilities that solve the problems creatively in natural situations (Hussein, 2012). Moreover, multiple intelligences proved their effectiveness in taking into account the individual differences, raising the students' level of achievement, expanding the teacher's teaching strategies, taking into account the different intelligences of students and their learning styles, and providing plans and teaching methods that grow the different sides of students' intelligences (Alhamuddin \& Bukhori, 2016).

Gardner considered that thinking is the processes of the mind in handling the situation content to reach a solution. According to him, a learning style is the group of intelligences and thus, the development of one or all of them facilitates the thinking processes of students. However, Gardner has criticized the intelligence tests that measure intelligence as a general mental ability (IQ), and considered to be culturally biased, because they measure only two types of intelligences, which are linguistic and mathematical, and he argued that there is no one intelligence, but multipleintelligences. The intelligence measured by traditional methods defines one area, while multiple-intelligences are psychological abilities that influence and develop the individual's motivation, experience and cultural factors. Also, Fasko (1992) suggested that the results for multiple intelligences-based programs are bigger and better and students with learning disabilities can improve better (Al-Khafaf, 2011). 


\section{Problem Statement}

Education should not neglect thinking skills for students through indoctrination and memorization and neglecting all activities that build the student's experiences. Also, neglecting thinking in educational institutions lead to neglecting every activity outside the classroom. This leads to a reduction of similar learning opportunities for all students, because the construction of tests is limited to retrieving only memorized information and neglects individual differences. Thus, it affects the level of quality education that the student needs in the future. (Langer, 2004).

Atiyyah (2015) noted that the academic failure of university students is due to their inability to think abstractly in solving problems efficiently. In addition, the low level of thinking among students is due to what teachers do in the classroom, i.e. the deficiency in transferring the academic content, like (What to think about?) while it is supposed to be based on understanding and evaluation of the scientific material (How to think?). Also, every student can learn how to think if he/she was granted the opportunity of training and actual adequacy practice (Atiyyah, 2015). The development of thinking skills is considered a fundamental pillar and cornerstone of all aspects of educational learning, because it prepares students for future life and qualifies them to be good and productive individuals.

\section{Study Objectives}

This study has two main objectives as follows:

1. To determine if there is an effect of relationship between multiple-intelligence and thinking patterns through developing creative thinking among 10th grade students in private schools in Abu Dhabi.

2. To determine if there is an indirect relationship between the study variables i.e multiple-intelligence, thinking patterns and creative thinking among the 10th grade students in private schools in Abu Dhabi.

\section{Multiple Intelligences Theory}

The concept of multiple-intelligence theory is considered very important. This theory changed looking at intelligence generally and introduced another concept for intelligence. It has also rejected the single general intelligence idea and showed the existence of multiple intelligences that the learner has, which is considered as the mental capabilities that learners have and can use in their everyday lives. This theory was developed by Gardner, which enables educators to find teaching methods that help learners master the subjects and create an exciting classroom environment, 
including activities and assessment tools that respond to eight types of intelligences, which are linguistic, logical, spatial, musical, natural, bodily-kinesthetic, interpersonal, and intrapersonal (Al-Khuzaie \& Al-Amrani, 2013). While Al-Samaili and Al-Zahrani (2013) believed that the theory of multiple intelligences is one of the important educational theories reached to by Gardner and published in his book "Frames of Mind". Since then, the theory has evolved from theoretical to practical aspect. The researchers work in each field to use them experimentally and practically to make maximum use of the development of family members and school students. (Al-Samaili \& Al-Zahrani, 2013)

This theory is one of the theories that have a great role in the educational aspect, as it focused on things that were overlooked by other theories. Many talents were overlooked because of the reliance on individual assessment and intelligence tests. However, this theory helps to uncover individual abilities and differences. The educational importance of the theory of multiple intelligences is illustrated as follows. The researcher showed that this theory has a logical side (practical) which is not indispensable in the educational ground because it covers many of the sides related to the learners' studying and practical times. This makes the learner varies his educational choices so that they can cover many of the multiple intelligences, which will be as educational episodes that the student will learn from and in the end make for a bridge to the student's goals. This theory is based on the processes that the mind follows in order to solve the problem. It attempts to describe how individuals use their multiple intelligences to solve a problem and it helps teachers expand their strategies to reach as many learners as possible. Also, it has no specific rules, except for the requirements proposed by the cognitive components of each type of intelligence. It proposes solutions that enable teachers to design new curricula and to handle and present content differently. (Al-Rubaie, 2013)

Furthermore, Hussein (2018) explained that helping teachers to improve their performance in the education process and the possibility of adopting multiple intelligences as an input in teaching styles will take into consideration the nature of the learners in the classroom. Moreover, this theory stems from the learners' interests and takes into account their preferences and abilities. It also guides all individuals to the job that suits their abilities and tendencies, improves students' achievement levels and raises their levels of interest towards educational content. Gardner believes that when providing information through multiple intelligences, it produces several things, including that it reaches as many learners as possible; students realize that they are more likely to express themselves and increase the ability of learners to 
present what they understood from the taught lessons in multiple ways (Hussein, 2018).

\section{Thinking Patterns}

The more intelligence is practiced by the learner through applying thinking skills the more thinking patterns are updated. There are three main types of thinking patterns including, visual thinking, creative thinking and critical thinking (Afaneh \& AlKhazindar, 2005). Visual thinking is one of the thinking patterns that educational institutions are interested in its development among students because of its many advantages. It is important to avoid hasty and impulse decisions and helps to give the best shot by taking full advantage of whatever knowledge, information, and skillset being possessed. While creative thinking is a different pattern of thinking which is a flexible thinking with the ability to change the state of mind, by changing the situation and the trend of ideas depending on the situation. It involves looking out for new ideas and concepts based on your past learning and life experiences. Critical thinking is a higher order, well-disciplined thought process, which involves the use of cognitive skills like conceptualization, interpretation, analysis, synthesis and evaluation for arriving at a valid, unbiased judgment. It is explained in details in the next section.

\section{Creative Thinking}

Creativity is a cognitive process with successive stages of production, which is to produce multiple solutions characterized by diversity and novelty in a supportive and harmonious environment. Creative thinking has a deep connection with creativity, where creativity describes the outcome while creative thinking describes the processes and mental skills for creativity, which is used by the individual to produce as many ideas as possible about the problem that he or she is facing, or the situation he or she is interacting with, these ideas are characterized by diversity, difference and non-repetition (Al-Rashidi and Al-Khaldi, 2015).

Psychologists and researchers of creative thinking perceive that the practice of creativity has sentimental tendencies as well as mental skills. Emotional orientations should be available along with cognitive skills and creative thinking, and it has components and skills that distinguish it from other types of thinking. The researchers almost unanimously agreed of the classification and components of creativity, some call them creativity skills, which include four fundamental skills of creative thinking (fluency, flexibility, originality and elaboration). (Armastrong, 2008) 
One of the most important foundations of the theories that studied creativity was Geschtal theory of creative thinking. The authors of this theory believe that creative thinking begins with a problem that the individual faces that is incomplete or deficient, and when thinking about solving it, everything is considered, examined within the overall framework, they see that it is insightful thinking, where the individual reaches the solution suddenly, and then, moves away from the problem and reaching the so-called flash insight. Looking at the problem for the first time will be different from the other times, the more we look at the problem, the more we will receive new information from reordering factors and components, which makes us change our opinion and see things we did not notice before. In the final stage, rebuilding the field is done to restore consistency to it (Attiyya, 2015; Ruzzuqi \& Abdulkarim, 2015).

Also, another important theory in creativity was Humanistic theory. The adopters of this theory, including (Maslow), believe that all individuals have the ability to innovate and that this ability is subject to the influence of the social climate in which they live. There are creative people who are self-fulfilling and other creative people with special talents. Moreover, creative people live their reality more than those who live in the world of stereotypical theories and beliefs, and creative people are more self-expressive, more natural, spontaneous and less articulate. Furthermore, there are two types of creativity: the first type is the one that leads to the production of new things which depends on talent and hard work, while the second type is the creation of self-realization. On the other hand, Rogers believes that the creative process is an authentic production that grows in the person's individuality, materials, events and life circumstances, because creativity cannot be achieved without producing something that can be observed and that this product must be authentic, creativity from his point of view depends on two conditions, which are mental integrity and mental freedom. In addition, he considered creativity as a new production that stems from the interaction between the individual and the different experiences he acquired. However, there is a weakness in this theory, in which that it gives creativity a romantic look and that it fulfills individual's humanity more than it is a particular mentality leads to a certain output. (Assaf, 2013)

\section{Factors Contributing to The Development of Creative Thinking}

Abdullah (2017) explained that there are a number of factors that can help in the development of creative thinking and abilities of learners, which are: 
Qualified teachers who are able to take care of creativity and creative minds and follow-up their students in and out of school, and communicate with their families to follow the development of their creativity.

Provide an educational environment that encourages creativity, which contains all the supplies of libraries, laboratories, computers, technologies and means of presentation.

Provide curricula with modern contents that are flexible and work on a comprehensive development of the personality of the learner, and is able to develop his/her imagination and enable him/her to develop hypotheses and discovery methods, so as to stimulate the mind and encourage research and experimentation.

Relying on assessment methods that emphasizes measuring creative abilities for learners and these measures are characterized by stability, objectivity, comprehensiveness and discrimination, that is, measuring the higher thinking levels of the students to whom creative thinking skills belong.

Conducting workshops and training courses for creativity which are equipped with all the means and techniques required for the processes of creativity.

Engaging creative students in activities and events that are characterized by depth and diversity and are under the supervision of those who have sufficient experience in creativity and care of creative minds.

Providing optional courses that respond to the students' creative tendencies and guide their path of choosing future career.

Providing programs enrichment in support of the content of the subjects that enrich the learning material in a way that contributes to the formation and development of creative abilities among learners.

Issue a special magazine or newspapers that include creative students' activities and achievements. (Abdullah, 2017)

Assaf (2013) demonstrated that psychologists and researchers of creative thinking perceive that the practice of creativity has sentimental tendencies as well as mental skills. Emotional orientations should be available along with cognitive skills and creative thinking, and it has components and skills that distinguish it from other types of thinking. The researchers almost unanimously agreed of the classification and components of creativity, some call them creativity skills, which include four fundamental skills of creative thinking (fluency, flexibility, originality and elaboration). Where Feldhusen in 1984 and Torrance in 1965 determined them by 
five skills, which are: fluency, flexibility, originality, elaboration and sensitivity to problems.

Another theory of creative thinking is the Psychoanalysis Theory. Jarwan (2014) demonstrated that Freud, the founder of this theory, believes that creativity is the expression of defensive tricks called (transcendence or sublimation), and through these defensive tricks, the individual expresses his potentials in a form that is accepted by society. Creativity arises as a result of psychological conflict at the beginning of the person's life (as a defensive trick) to counteract the libido energy which society does not accept to express. According to Freud, creativity is the creative person moving away from the familiar reality to an imaginary life, and he has linked creativity and other behaviors with the set of motives driven by the unconscious. If the person cannot express his/her desires and tendencies freely, those desires must proceed in other ways or be compensated (Jarwan, 2014).

\section{The Importance of Multiple-Intelligence and Creative Thinking Skills in Teaching}

Based on the theories and previous studies, there is a significant relationship between multiple-intelligence-based learning and creative thinking among students. For example, the study conducted by Yi, Sulaiman and Baki (2015) about the role of multiple intelligences and creativity in students' learning style to examine the relationship between creativity and intelligence. The study findings showed that students from both gender possessed high intelligence in common domains, namely interpersonal, followed by intrapersonal and musical. This study concluded that it is important to identify students' intelligence profile as well as their creativity level according to domains. This is to aid students learning, providing them with the optimum learning environment through their preferred learning medium and help them to achieve their fullest potential in their respective talented areas.

Also, Abdi and Rostami (2012) have studied the effect of multiple intelligences- based instruction on Students' creative thinking ability at 5 th grade in a primary school. The purpose of this study was to examine the effect of multiple intelligences- based instruction on students' creative thinking ability at 5th grade in primary school. The researchers have used Torrance's Creative Thinking Test as pre-tests and posttests. Results which were analyzed by covariance indicated that multiple intelligencesbased instruction significantly stimulated students' creative thinking ability. Hence, it was concluded that strategies founded on MI theory were more effective in improving students' creative thinking ability than traditional teaching. Moreover, Widiana and Jampel (2016) have conducted a study about improving students' creative thinking 
and achievement through the implementation of multiple intelligence approaches with mind mapping. This classroom action research aimed to improve the students' creative thinking and achievement in learning science. It was conducted through the implementation of multiple intelligences with a mind mapping approach and describing the students' responses. The findings showed positive results, where students felt happy in learning science through the implementation of multipleintelligences with mind mapping and this method has improved students' creative thinking.

Teaching based on multiple-intelligence has a great effect on students' learning and creative skills. Also, it helps to increase students' motivation to learn different subjects. However, there is a lack of studies investigating the effect in the social studies and national education subject. Hence, the current study aimed to investigate and prove that teaching based on the multiple-intelligence theory is more effective in improving students' creative thinking ability than traditional teaching in the subject of social studies and national education.

\section{The Relationship between Multiple-Intelligence and Thinking Patterns}

The researcher believes that there is a relationship between multiple-intelligence and thinking patterns. That is what many researchers and psychologists in their studies and researches showed, no researcher or student can deny that relationship. Intelligence does its role through thinking and affects it, and through intelligence thinking skills can be updated, growing thinking skills needs high intelligence from the individual.

Al-Sorour (2003) stated that thinking and intelligence are connected to each other and are fundamental to the learning process. Intelligence depends either on genes or early education or a combination of both. In addition, thinking is the skill practiced by intelligence through experience-based activities. This is the true relationship between intelligence and thinking.

The researcher sees that critical thinking must be integrated into the curriculum, and that it must be taught in schools. Students must know the critical thinking steps because they benefit their practicing and learning lives and make them aware thinkers of what happens around them. The teaching strategies must include these critical thinking. Training students in the steps of critical thinking, such as making assumptions, collecting and experimenting data, and arriving at results makes them successful researchers and thinkers in the future. Critical thinking can be taught in different ways and methods. Teachers must include critical thinking in their teaching 
methods and not teach in the traditional or old-fashioned way of teaching because information change from time to time but teaching students in new ways will stimulate the students' thinking skills that will definitely help them in the future.

Teaching thinking helps students to discover how to use their multiple intelligences in the taught lesson. Teaching students the practical applications needed to enhance and improve the weaknesses in their intelligence abilities and give them the opportunity to use their different types of intelligences in the classroom. It is also important to create strategies to help them translate their knowledge into forms of intelligence and conduct special events for students to discover their multiple intelligences and help them perform exercises to learn how to activate each type of intelligence (Atiyyah, 2015).

\section{Research Design}

The current study uses the descriptive approach. The descriptive approach explains and describes what is really happening, and is concerned with the conditions and relationships that exist, prevailing practices, current procedures and processes, beliefs, different viewpoints and individuals 'directions about an issue. Descriptive research includes surveys and exploratory interrogations in different fields. The primary goal is to describe the current state of a phenomenon. Therefore, the researcher compares the differences between groups or the relationships between them and the variables in this type of research differ in type more than in the amount (Allam, 2001).

Also, this study has used the Structural Equation Modeling Method (SEM). It depends on a descriptive model of the relationships between different variables being studied, is one of the best descriptive statistical methods that can be used in analyzing the correlation coefficients between the variables to direct or indirect effects. In addition, the evaluation of the relative importance of the independent variables in determining or interpreting the total differences of the dependent variable becomes clear when it is studied within the framework of the structural equation modeling. (Sahrawi \& Busalb, 2016)

\section{Sampling Method}

The study sample consisted of 350 secondary level students studying in private schools in Abu Dhabi. Table (1) below shows the distribution of the study sample in Abu Dhabi private schools. 
Table 1. The Numbers of Tenth Grade Students in Abu Dhabi

\begin{tabular}{llll}
\hline School name & No. of males & No. of females & Total \\
\hline Al-Rawafid & 40 & 60 & 100 \\
\hline Al-Shuhub & 0 & 35 & 35 \\
\hline Al-Mamurah & 0 & 50 & 50 \\
\hline $\begin{array}{l}\text { Al Bateen (Aldar } \\
\text { Company) }\end{array}$ & 60 & 50 & 110 \\
\hline $\begin{array}{l}\text { Gling (ADNOC } \\
\text { Corporation }\end{array}$ & 100 & 55 & 155 \\
\hline Total & 160 & 190 & 350 \\
\hline
\end{tabular}

Source: UAE Ministry of Education 2019

(https://www.moe.gov.ae/En/Pages/Home.aspx)

\section{Research Instruments}

The following instruments were used in this study:

Howard Gardner's Multiple-Intelligence Survey Instrument: The researcher found that Gardner scale is best suited to measure multiple intelligences, where many studies have used this scale, including: (Al-Jawaldeh, Al-Qamish, \& Muqableh, 2011; Al-Shami, Nubi, \& Al-Hamad, 2013; Rayyan, 2013; Armstrong, 2008). The scale consists of eight types of intelligence which are, linguistic, logical, interpersonal, intrapersonal, musical, spatial, naturalistic and bodily kinesthetic.

Thinking Patterns Scale: The researcher found the scale of Torrance's test which was standardized by (Muhammad Thabet Ali Al-Din) as well as the scale of (Ahmed AlMutairi) who developed it with reference to the study of (Alhamuddin \& Bukhori, 2016). In addition to the scale of (Farouk Abdel Salam and Mamdouh Suleiman) which was standardized by (Afaneh \& Al-Khazindar, 2005). It is best suited to measure thinking patterns, as many studies have used this scale. The scale consists of three dimensions, namely critical thinking (recognition of assumptions, interpretation, evaluation of arguments and deduction), creative thinking and visual thinking (successive matrix, visual symmetry, visual succession, and visual object recognition). The point-scale used are (yes, no, strong, weak, true and false).

\section{Research Findings}

The results showed significant positive relationship between multiple intelligences (IV) and thinking patterns (DV) through creative thinking (MV). Direct significant positive relationships were found between interpersonal intelligence (IV) and thinking patterns (DV) ( $\mathrm{r}=.241)$; natural intelligence (IV) and thinking patterns (DV) 
$(\mathrm{r}=.113)$; musical intelligence (IV) and thinking patterns (DV) ( $\mathrm{r}=.000)$; bodilykinaesthetic intelligence (IV) and thinking patterns (DV) ( $\mathrm{r}=.000)$.

Then, to further establish the full or partial mediation of creative thinking skill. Sobel test was conducted to determine the overall significant mediating effect of creative thinking skills on relationship between multiple intelligence factors and thinking pattern. The outcome of Sobel test analysis and two tail probability value revealed similar findings to that of structural equation model analysis on mediating role of creative thinking in the relationship between Musical intelligence and thinking pattern. The result reveals that creative thinking skill $(\beta=0.771, \mathrm{P}=0.0000)$ mediates the relationship between musical intelligence and thinking pattern. Similar Sobel result was also obtained for bodily kinesthetics. Creative thinking skill $(\beta=0.771$, $\mathrm{P}=0.0000$ ) mediates the relationship between bodily kinesthetics intelligence and thinking pattern. More so, the outcome of Sobel test analysis and two tail probability value revealed similar findings to that of structural equation model analysis. Similarly, Sobel mediating test shows that creative thinking $(\beta=0.771, \mathrm{P}=0.0458)$ mediates the relationship between interpersonal intelligence and thinking pattern. In addition, Sobel mediating test shows that creative thinking $(\beta=0.771, \mathrm{P}=0.0192)$ mediate the relationship between Natural- intelligence and thinking pattern.

\section{Discussion}

The results show that the path coefficient of direct between multiple-intelligences and creative thinking variables was of practical importance and statistically significant. This indicates that multiple intelligence factor-musical and bodily kinesthetic intelligence significantly influence students' creative thinking skill. Previous literatures have revealed that musical and bodily kinesthetic intelligence of students have effects on creative or innovative thinking capacity of individual thinking skills of students (Hilal, 2008), while some studies such as (Al-Sarraj's study, 2011) did not find any direct influence of musical and bodily kinesthetic intelligence on creative thinking skill. There is evidence showing the direct effects of musical and bodily kinesthetic intelligence on creative thinking skill (Ahmed, Seman, Awang \& Sulaiman, 2014). On the other hand, interpersonal, intrapersonal, verbal linguistic, spatial, natural and logical intelligence have been found to have direct influence on creative thinking skill (Al-Sayyed, 1994). This is true when teacher wants to work on the thinking skills of students, he/she must take into consideration the role of musical and bodily kinesthetic intelligence capacity of the student (Hilal, 2008; Najm, 2007). The study of (Loori, 2005) revealed that there is an impact of multiple intelligence, including musical intelligence on the development of learning styles and patterns of 
thinking, including creative thinking. The studies of (Al-Rashidi \& Al-Khaldi, 2015; Mahmoud \& Al-Maharmah, 2012) have explained the influence of multipleintelligences, including bodily-kinesthetic intelligence on the development of creative thinking among students. The study conducted by (Winarti, Yuanita \& Nur, 2019) showed the effect of bodily-kinesthetic intelligence in particular and multipleintelligences in general on the development of thinking skills, including creative thinking among secondary school students.

It has been shown that there is a direct relationship between linguistic intelligence and thinking patterns, as well as an indirect relationship between bodily-kinesthetic and musical intelligence and creative thinking, and also a direct relationship with the rest of the multiple intelligences and creative thinking, when teachers are activated to teach thinking skills in the lessons and studies in the secondary stage (tenth grade). Moreover, the researcher believes that the relationship between multiple intelligences and thinking patterns and skills is most evident in linguistic, musical and bodily-kinesthetic intelligence, as their effects appear clearly, and the teacher can highlight them easily. This does not reduce the existence of the relationship between the rest of the multiple intelligences and the thinking skills and patterns, but rather does not appear at times. Clearly for the learners, it may need many accurate measures to measure them and also to distinguish most of the learners with linguistic, musical and bodily-kinesthetic intelligence, as it constitutes a large proportion of their learning. However, educational systems do not give much attention to the development of the rest of the multiple intelligences, such as natural and social intelligence. This leads to the creation of weakness and lack of strong association between these multiple intelligences and thinking skills and patterns.

Also, the results show that the path coefficient of direct between creative thinking skills and thinking pattern variables was of practical importance and statistically significant. This indicates that creative thinking skill significantly influence students' thinking pattern. Literatures have revealed that creative thinking skill of students have effects on thinking pattern of students (Widiana \& Jampel, 2016), while some studies such as (Foong, Shariffudin \& Mislan, 2012) did not find any direct influence creative thinking skill on thinking pattern. There are evidences showing the direct effects of creative thinking skills on thinking pattern (Al-Saliti, 2006).

\section{Conclusion}

This study has added a new perspective to current literature on multiple intelligence in teaching and learning by testing the mediating effect of creative thinking. The results of this study have demonstrated a strong and positive relationship between 
the predictors and criterion variables. Multiple intelligence factors--verbal linguistic, bodily-kinesthetics, intra and interpersonal intelligence, logical, musical, and natural intelligence indirectly influence thinking pattern through creative thinking skills. Thus, it can be asserted that multiple intelligence had a significant and positive direct influence on thinking pattern via creative thinking skills. Hence, it can be concluded that the proposed model supported causal relationship between multiple intelligence factors, creative thinking skills and thinking pattern of students in school. It is recommended to conduct further studies on multiple intelligences, thinking skills, and thinking patterns applied on different academic levels. It is also important to study the relationship and linkage between the study variables and other variables such as learning styles and educational subjects and curricula to prove the necessity of including multiple intelligences and thinking skills \& patterns in school curricula, textbooks and class activities.

\section{References}

[1] Abdi, A., \& Rostami, M. (2012). The Effect Multiple Intelligences-Based Instruction on Student's Creative Thinking ability at 5th Grade in Primary School. Procedia - Social and Behavioral Sciences, 47, 105-108. doi:10.1016/j.sbspro.2012.06.621

[2] Abdullah, R. (2017). Teaching Thinking Through Reading (2nd ed.). Cairo: Al-Dar Al-Masriyyah Al-Libnaniyyah.

[3] Abu-Hashim, A. (2007). List of multiple-intelligence for the global construction of intelligences in the light of Gardner's theory and its relationship to self-efficacy, problem solving and academic achievement among university students. Journal of the Faculty of Education. Zagazig University, 1(55), 171-242.

[4] Afaneh, I., \& Al-Khazindar, N. (2005). Classroom Teaching with MultipleIntelligence. Amman: Dar Al-Masirah.

[5] Ahmad, A. R., Seman, A. A., Awang, M. M., \& Sulaiman, F. (2014). Application of Multiple Intelligence Theory to Increase Student Motivation in Learning History. Asian Culture and History, 7(1). doi:10.5539/ach.v7n1p210

[6] Alhamuddin, A., \& Bukhori, B. (2016). The effect of multiple intelligencebased instruction on critical thinking of full day Islamic elementary schools' students. Ta'dib, 21(1), 31. doi:10.19109/td. v21i1.590

[7] Aljawaldh, F., Al-Qamish, M., \& Al-Muqablah, A. (2011). The level of talented students' teachers exercising multiple-intelligence in the classroom. Al- 
Quds Open Journal for Educational and Psychological Research and Studies, 1(1). Amman Arab University, Jordan.

[8] Al-Khafaf, I. (2011). Multiple Intelligences: An Applied Program (1st ed.). Amman: Dar Al-Manahij Publishing House.

[9] Al-Khuzaie, A., \& Al-Amrani, A. (2013). The effectiveness of teaching through activities of multiple intelligences in developing scientific thinking in physics for fourth-grade students of science. Kufa Studies Journal, 1(31), 253-283.

[10] Al-Otaibi, K. (2007). The effect of using some parts of the Kurt program in developing critical thinking skills and improving the level of academic achievement of a sample of secondary school students in Riyadh, unpublished doctoral thesis. Umm Al-Qura University, Makkah.

[11] Al-Rashidi, H., \& Al-Khaldi, M. (2015). The level of creative thinking among talented students in the secondary level in Tabuk in the light of some variables. The second international conference for talented and talented students, United Arab Emirates University, United Arab Emirates.

[12] Al-Rubaie, I. (2013). The effectiveness of an educational program according to multiple intelligences in understanding and acquiring mathematical concepts and reasoning for second-grade middle school students, unpublished doctoral thesis. University of Baghdad, Iraq.

[13] Al-Saliti, F. (2006). Critical and Creative Thinking and Cooperative Learning Strategy in Teaching Reading, Amman: A wall of the international book.

[14] Al-Samaili, H., \& Al-Zahrani, M. (2012). The effect of teaching according to multiple intelligences in forming a positive trend towards science subject for second year middle school students. Ministry of Education, Saudi Arabia.

[15] Al-Sarraj, A. (2011). The differences in multiple-intelligence and patterns of thinking between gifted and ungifted students in Jordan, unpublished $\mathrm{PhD}$ thesis. Amman Arab University, Jordan.

[16] Al-Sayyed, F. (1994). Intelligence from a New Perspective (5th ed.). Cairo: Dar Al-Fikr Al-Arabi.

[17] Al-Shami, J., Nubi, A., \& Al-Hamad, M. (2013). Designing electronic activities according to the theory of multiple intelligences in the talented education course and its impact on achievement and the motivation towards learning among students of the Arab Gulf University. The third international conference on electronic e-learning, Riyadh, Saudi Arabia. 
[18] Al-Sorour, N. (2003). An Introduction to the Education of the Talented and Gifted Individuals (1st ed.). Amman: Dar Al-Fikr Al-Arabi for publication and distribution.

[19] Armastrong, T. (2008). Multiple intelligence in the classroom. Alexandria, association for prevision and curriculum development. Arbor, Michigan, USA.

[20] Assaf, J. (2013). Attitudes of social studies teachers towards developing creative thinking skills among middle school students in the Directorate of the Third Amman Education. Journal of the Islamic University for Educational and Psychological Studies, 20(1), 269-292.

[21] Atiyyah, M. (2015). Thinking: Types, Skills, and teaching strategies (1st ed.). Cairo: Al-Dar Al-Masriyyah Al-Libnaniyyah.

[22] Foong, L. M., Shariffudin, R. S., \& Mislan, N. (2012). Pattern and relationship between multiple intelligences, personality traits and critical thinking skills among high achievers in Malaysia. International Conference on e-Education, $e$-Business, e-Management and e-Learning IPEDR, 27. Press, Singapore.

[23] Hilal, M. (2008). Thinking skills and strategic planning and how to link the present and the future. Damascus: Center for Performance and Development, Syria.

[24] Hussein, A. (2012). The effect of using some teaching strategies based on the theory of multiple intelligences in supporting the educational activities and developing creative thinking and the direction towards school among students of community education schools. Journal of the College of Education, 1(95).

[25] Hussein, T. (2018). The comprehensive guide to thinking skills (4th ed.). Amman: DeBono Thinking Center.

[26] Jarwan, F. (2007). Teaching thinking, Concepts and Applications (1st ed.). Amman: Dar Al-Fikr for publication and distribution.

[27] Jarwan, F. (2014). Talent, Excellence and Creativity (3rd ed.). Amman: Dar Al-Masirah.

[28] Langer, J. (2004). Let's Teach our Children the Sweetness of Thinking (1st ed.). Translated by: Sawsan Tabba. Riyadh: Obeikan Library.

[29] Loori, A. (2005). Multiple intelligence: a comparative study between the preferences of male and female, society for personality research, social behavior and personality. (1), 77- 89. 
[30] Mahmoud, A., \& Al-Maharmah, L. (2012). The Level of multiple intelligences for special education teachers in Jordan. The International Educational Journal, 1(10).

[31] Najm, H. (2007). The level of mathematical thinking and its relationship to some multiple intelligences among eleventh graders in Gaza, unpublished Master Thesis. Islamic University, Gaza.

[32] Rayyan, A. (2013). Types of multiple intelligences among secondary school students in Hebron, Palestine. Al-Aqsa University Journal, 17(1), 193- 234.

[33] Ruzzuqi, R., \& Abdul-Karim, S. (2015). Thinking and its Patterns (1st ed.). Amman: Dar Al-Masirah.

[34] Ruzzuqi, R., \& Abdul-Karim, S. (2015). Thinking and its Patterns (2ne ed.). Amman: Dar Al-Masirah.

[35] Sahrawi, A., \& Busalb, A. (2016). Structural Modeling (SEM) and the validity of psychological and educational research. The global construction model for the competencies of administrative facilitation in the educational institution. Psychological and Educational Sciences Journal, 3(2), 61-91.

[36] Widiana, I. W., \& Jampel, I. N. (2016). Improving students' creative thinking and achievement through the implementation of multiple intelligence approach with mind mapping. International Journal of Evaluation and Research in Education (IJERE), 5(3), 246. doi:10.11591/ijere.v5i3.4546

[37] Winarti, A., Yuanita, L., \& Nur, M. (2019). The effectiveness of multiple intelligences based teaching strategy in enhancing the multiple intelligences and science process skills of junior High School students. Journal of Technology and Science Education, 9(2), 122. doi:10.3926/jotse.404

[38] Yi, H. Y., Sulaiman, T., \& Baki, R. (2015). The role of multiple-intelligence and creativity in students' learning style. International Journal of Sustainable Development, 2(8). Retrieved from ISSN 1923-6662 